www.jmscr.igmpublication.org

Index Copernicus Value: 79.54

ISSN (e)-2347-176x ISSN (p) 2455-0450

crossref DOI: https://dx.doi.org/10.18535/jmscr/v7i6.127

\title{
Fibrothecoma of Ovary with Elevated Ca125 Levels and Ascitis - A Case Report
}

\author{
Authors \\ Parveen Rana Kundu ${ }^{1}$, Amrita Kulhria ${ }^{2 *}$, Swaran Kaur ${ }^{3}$, Monika Breta Gathwal ${ }^{4}$, \\ Anu Sharan', Anjali Sindhu' \\ ${ }^{1,4}$ Associate Professor, Department of Pathology, B.P.S. Government Medical College For Women, Khanpur \\ Kalan, Sonipat Haryana \\ ${ }^{2}$ Senior Resident, Department of Pathology, B.P.S. Government Medical College For Women, Khanpur \\ Kalan, Sonipat Haryana \\ ${ }^{3}$ Professor \& Head, Department of Pathology, B.P.S. Government Medical College For Women, Khanpur \\ Kalan, Sonipat Haryana \\ ${ }^{5,6}$ Junior Resident, Department of Pathology, B.P.S. Government Medical College For Women, Khanpur \\ Kalan, Sonipat Haryana \\ *Corresponding author
} Amrita Kulhria

Addresses: Department of Pathology, B.P.S. Government Medical College For Women, Khanpur Kalan, Sonipat Haryana. 131305, India

\section{Abstract}

Introduction: Ovarian fibrothecomas are uncommon, benign tumors of gonadal stromal cell origin. They account for 3-4\% of all ovarian neoplasm and are rarely malignant. CA 125 is usually normal.

Case Report: A case of ovarian fibrothecoma in a postmenopausal woman who presented with complains of something coming out of vagina (uterine prolapse), abnormal uterine bleeding and abdominal distension for 6 months. CA 125 levels were also raised.

Conclusion: Fibrothecomas are solid, uncommon ovarian neoplasm. It is to be differentiated from other solid neoplasm of ovary in post menopausal women.

Keywords: Fibrothecoma, Ovary, CA 125.

\section{Introduction}

Sex cord-stromal tumors are a distinct group of ovarian neoplasm accounting approximately $8 \%$ of all ovarian neoplasms. ${ }^{[1]}$ The cell of origin of these tumors is either coelomic epithelial cells or the mesenchymal cells of the embryonic gonads. The most common types are granulosa cell tumors, fibrothecomas and Sertoli-Leydig cell tumors. Fibrothecomas are rare sex-cord stromal tumors of ovary and constitutes only 3-4\% of all neoplasm. They have histological features of both i.e. fibromas and thecomas and hence the nomenclature. The age of presentation is middle aged to postmenopausal women and is usually benign. ${ }^{[2]}$ Histologically, these tumors comprise fibrous and thecomatous component. The fibrous 
element consists of bland spindle, oval or round cells arranged in fascicles and variable amount of collagen. The thecomatous component consists of polygonal cells with a moderate to abundant amount of clear cytoplasm which are arranged either in small clusters or singly dispersed. Surgical resection is the treatment of choice and is generally associated with a good prognosis. ${ }^{[3]}$ Tumorectomy is indicated for young patients, if possible; and total hysterectomy with bilateral salpingo-oophorectomy is the treatment of choice for perimenopausal and menopausal patients.

Here, we describe a case of a unilateral ovarian fibrothecoma in a 60 years old female who presented with complains of something coming out of vagina (uterine prolapse), abnormal uterine bleeding and abdominal distension for 6 months.

\section{Case Report}

A 60-year-old postmenopausal woman presented to the gynaecology OPD with complains of something coming out of vagina (uterine prolapse), abnormal uterine bleeding and abdominal distension for 6 months. On local examination of abdomen and pelvis, a large nontender, well-defined and fixed mass measuring approximately $8 \times 8 \mathrm{~cm}$ was palpated in the left side of pelvis. Uterovaginal descent was observed on per speculum examination and a hard, irregular and non-1tender mass was felt in the pouch of douglas per vaginally. Ultrasonography of abdomen and pelvis and CA-125 levels was advised. Ultrasonographically, a uterine fibroid measuring $8 \times 6 \mathrm{~cm}$ and another mass measuring $11 \times 9.9 \times 9.8 \mathrm{~cm}$ was observed in left adnexal region. Ascitis was also observed. The left sided ovary could not be visualised and fallopian tube appeared to be normal. Right sided adenexa was normal. CA 125 levels were found to be raised (90 $\mathrm{U} / \mathrm{mL}$ (reference range $<35 \mathrm{U} / \mathrm{ml}$ ).

The patient underwent total hysterectomy with bilateral salpingo-oophorectomy and infracolicomentectomy and the specimens were sent for histopathological examination. Grossly, myometrium showed a well encapsulated fibroid measuring $7.8 \times 5.5 \mathrm{~cm}$, cut section of which was grey white and had whorling. Left ovarian mass measuring 11 x $10 \mathrm{~cm}$ was observed. Outer surface was grey white and smooth with an intact capsule. Cut section was grey white, firm and showed whorling pattern (Figure 1). Histopathology of left ovarian mass revealed closely packed oval to spindle cells arranged in whorled and storiform pattern with few focal areas showing cells with vacuolated cytoplasm and myxoid change (Figure 2). On immunohistochemical analysis, CD 10 and inhibin showed focal positivity. The right sided adnexa and left fallopian tube were unremarkable. Uterine mass showed features of leiomyoma. A diagnosis of fibrothecoma of left ovary and leiomyoma of uterine corpus was made.

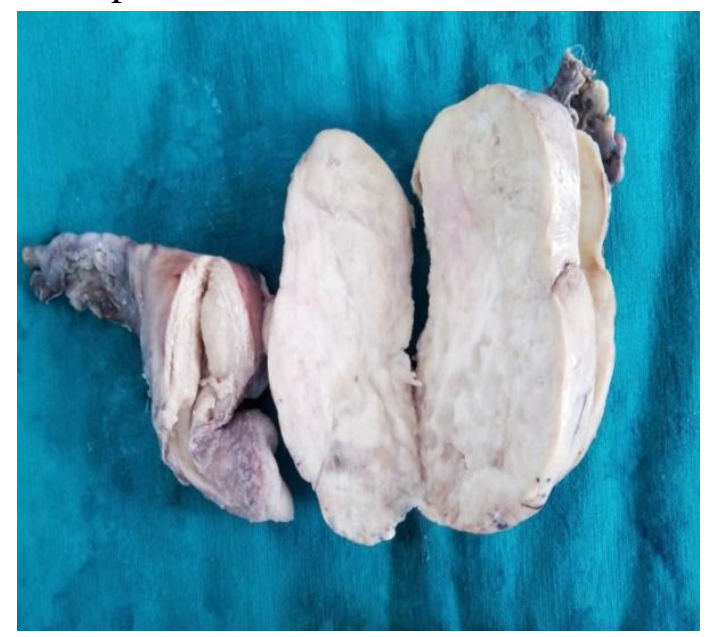

Figure 1 Cut surface of the ovarian mass showing firm, grayish white area with few yellow areas.

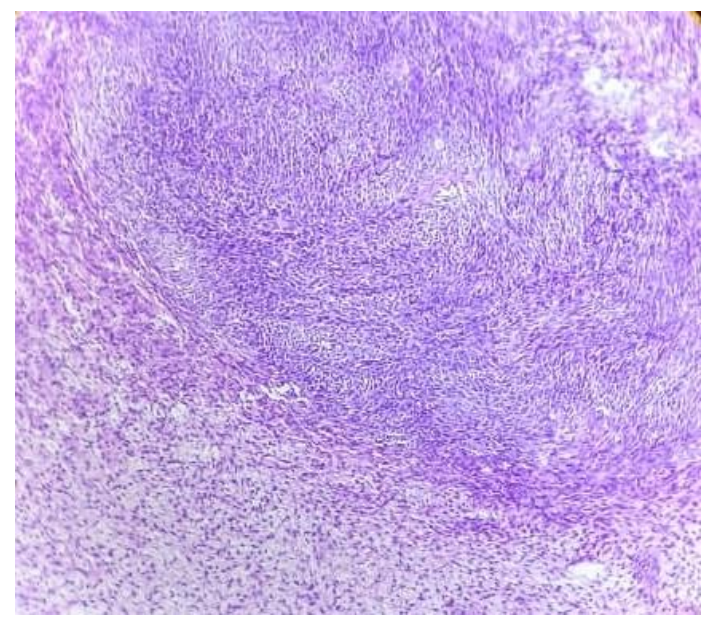

Figure 2: Hypercellular areas with spindle cells and cells with abundant pale or vacuolated cytoplasm (theca cells) (H\&E; 10X). 


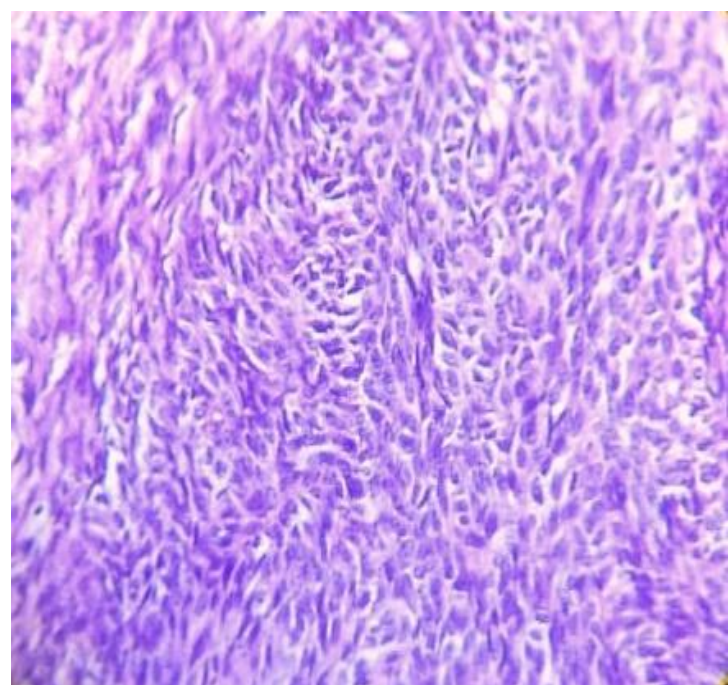

Figure 3: High power view (H\&E; 40X)

\section{Discussion}

Ovarian fibrothecomas are rare tumors of gonadal stromal cell origin. They occur predominately in older postmenopausal women and and $90 \%$ of the cases are unilateral. ${ }^{[2]}$ Patients most commonly present with a pelvic mass, pelvic pain and metrorrhagia $\cdot{ }^{[4]}$ Endocrine manifestations can be there in the form of uterine enlargement and endometrial thickening as fibrothecoma displays estrogenic activity. ${ }^{[5,6]}$ Fibrothecomas can be associated with ascites and elevated CA 125 levels as it was in our case. ${ }^{[7-9]}$ However levels comes to normal after surgical removal which was observed in our case also. Meigs syndrome is observed with $1-10 \%$ of ovarian fibromas. ${ }^{[2]} \mathrm{CA}$ 125 is a carbohydrate antigen, which is generally described as a marker of nonmucinous ovarian neoplasms. It can also be elevated in patients with nonovarian malignancies and nonneoplastic conditions such as endometriosis and cirrhosis. The elevation of CA 125 in our case may be caused by just the irritation of peritoneum (mesothelium) as this antigen is expressed on mesothelium. ${ }^{[10]}$

Histologically, fibrothecomas have fibrous and theca component. It is difficult to differentiate between fibrothecoma from pure fibromas and thecomas as there is morphological overlap. There are some points which favour one over other. Extensive deposited collagen and fewer cells with cytoplasmic vacuolization favours fibrothecoma over thecoma. When compared with fibroma, fibrothecoma has plumper cells with paler cytoplasm and higher cellularity. These tumors are usually benign but in susceptible individuals, a fibrosarcoma may arise in a fibrothecomatous tumor. ${ }^{[1]}$ The main histologic features of fibrosarcoma of the ovary are hypercellularity and brisk mitotic activity of 6 to 8 per 10 high-power fields. The cells are arranged in herring bone pattern. The cells are arranged in a herringbone pattern. ${ }^{[2]}$

Differential diagnosis of fibrothecomas on gross includes pedunculated and intraligamentous leiomyomas and other solid ovarian masses such as brenner tumors, dysgerminomas and granulosa cell tumors. Clinical and histopathological correlation excludes all these entities. Leiomyoma, Brenner tumor and Granulosa cell tumor $(95 \%)$ occurs in adult life as in our case. Histopathology is gold standard to differentiate among them. Leiomyoma shows interlascing fascicles of cigar shaped cells. Brenner tumor is characterized by coffee bean nucleus of tumor cells. Granulosa cell tumor have characterstic Call Exner bodies which was not there in our case. Dysgerminoma is usually in adolesecent girls and early adult life which was against to our case. It is characterized by nest of clear tumors cells separated by fibrous septa with infiltrating lymphocytes. The tumor cells have centrally placed nuclei with coarse granular chromatin.with prominent one or more nucleoli and clear cytoplasm.

Fibrothecomas can show massive oedema and myxoid change. ${ }^{[12-15]}$ So, these tumors must be differentiated from the oedema of the ovary, ovarian myxoma. The mean age of presentation of oedema is 22 years ${ }^{[15]}$, whereas $84 \%$ of the thecoma patients are postmenopausal and fibroma occurs most frequently during middle age. ${ }^{[16]}$ Oedema of the ovary is characterized by a proliferation of ovarian stromal cells with marked intercellular oedema preserving the overall structure of both the ovarian cortex and medulla. Ovarian myxoma shows extensive myxoid change 
and proliferation of spindle and stellate cells in myxoid areas interspersed with areas of hemorrhage, fibrosis, vascular spaces. ${ }^{[13]}$

\section{Conclusion}

Fibrothecomas are solid, uncommon ovarian neoplasm. These lesions often occur in older postmenopausal patients. Clinical and radiological studies remain the best preoperative approach currently available for ovarian tumors. However, histopathology remains gold standard for the definitive diagnosis and to differentiate among other solid ovarian tumors in post menopausal women.

Financial support and sponsorship: Nil.

Conflicts of interest: There are no conflicts of interest.

\section{References}

1. Outwater EK, Wagner BJ, Mannion C, McLarney JK, Kim B. Sex cord-stromal and steroid cell tumors of the ovary. Radiographics 1998; 18: 1523-46.

2. Chechia A, Attia L, Temime RB, Makhlouf T, Koubaa A. Incidence, clinical analysis, and management of ovarian fibromas and fibrothecomas. Am J ObstetGynecol 2008; 199(473): 1-4.

3. Dhull A, Kaushal V, Mathur S, Agarwal R. Fibrothecoma of the Ovary- A Rare Case Presentation. The Internet Journal of Third World Medicine 2010; 9(2): 1-4.

4. Bazot M, Ghossain MA, Buy JN, Deligne L, Hugol D, Truc JB, et al. Fibrothecomas of the ovary: CT and US findings. J Comput Assist Tomogr 1993; 17: 754-59.

5. Imaoka I, Wada A, Kaji Y, Hayashi T, Hayashi $M$ et al. Developing an MR imaging strategy for diagnosis of ovarian masses. Radiographics 2006; 26: 1431-48.

6. Takeshita T, Shima H, Oishi S, Machida $\mathrm{N}$, Yamazaki $\mathrm{K}$ et al. Ovarian fibroma (fibrothecoma) with extensive cystic degeneration: unusual MR imaging findings in two cases. Radiat Med 2005; 23: 70-74.

7. Tavassoli FA, Devilee P, eds. Pathology and Genetics of Tumours of the Breast and Female Genital Organs. Lyon, France: IARC Press; 2002.World Health Organization Classification of Tumours; vol 5.

8. Renaud MC, Plante M, Roy M. Ovarian thecoma associated with a large quantity of ascites and elevated serum CA 125 and CA 15-3. J Obstet Gynaecol Can. 2002; 24: 963-65.

9. Young RH, Scully RE. Sex cord stromal, steroid cell and other ovarian tumors with endocrine, paraendocrine and paraneoplastic manifestations. In: Kurman RJ, ed. Blaustein's Pathology of the Female Genital Tract. 5th ed. New York, NY: Springer-Verlag; 2002.

10. McCluggage WG, Sloan JM, Boyle DD, Toner PG. Malignant fibrothecomatous tumour of the ovary: diagnostic value of anti-inhibin immunostaining. J Clin Pathol 1998; 51: 868-871.

11. Lee H, Ahmed Q. Fibrosarcoma of the ovary arising in a fibrothecomatous tumor with minor sex cord elements: a case report and review of literature. Arch Pathol Lab Med. 2003; 127: 81-84.

12. Samanth KK, Black WC. Benign ovarian stromal tumors associated with free peritoneal fluid. Am J Obstet Gynecol 1970; 107: 538-45.

13. Costa MJ, Morris R, DeRose PB, Cohen C. Histologic and immunohistochemical evidence for considering ovarian myxoma as a variant of the thecoma-fibroma group of ovarian stromal tumors. Arch Pathol Lab Med 1993;117: 802-8.

14. Troiano RN, Lazzarini KM, Scoutt LM, Lange RC, Flynn SD et al. Fibroma and fibrothecoma of the ovary: MR imaging findings. Radiology 1997; 204: 795-98. 
15. Nogales FF, Martin-Sances L, MendozaGarcia E, Salamanca A, Gonzalez-Nunez MA et al. Massive ovarian oedema. Histopathology 1996; 28: 229-34.

16. Scully RE, Youg RH, Clement PB. Tumors of the ovary, maldeveloped gonads, fallopian tube and broad ligament. Washington DC, AFIP, 1996. P. 189-201. 